\title{
Regional differences of sudden cardiac death in sports. Experiences from German and Swiss registries
}

\section{CARDIOLOGY / PREPARTICIPATION / SPORTS MEDICINE / TEAM MANAGEMENT}

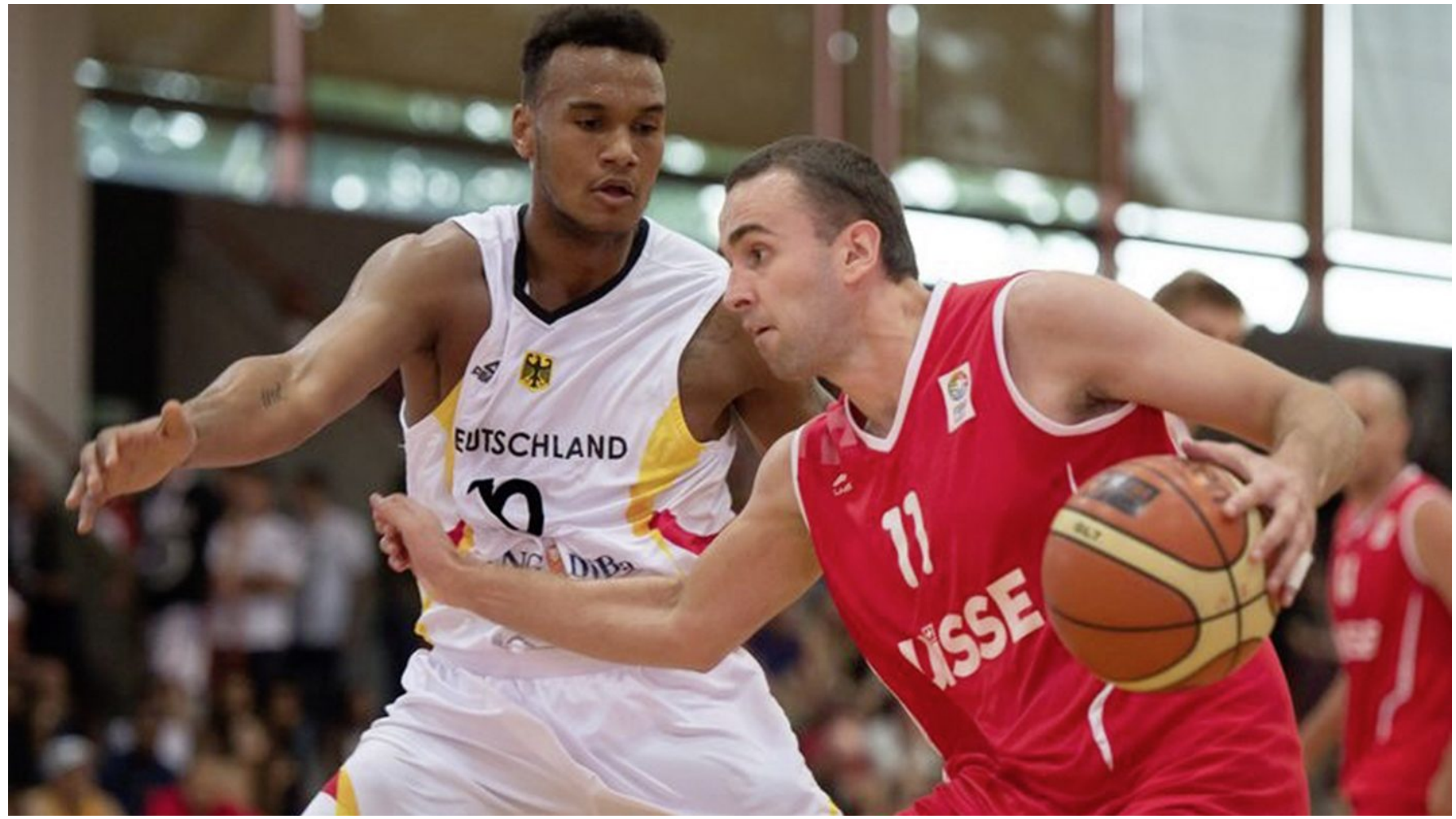

Bohm $\mathbf{P}^{1}$, Wilhelm $\mathbf{M}^{2}$

${ }^{1}$ University Heart Center Zurich, Department of Cardiology, Zurich, Switzerland

${ }^{2}$ Department of Cardiology, Interdisciplinary Center of Sport \& Exercise Medicine, Bern University Hospital, Bern, Switzerland

\section{Abstract}

Sudden death of an athlete is the most devastating medical event in sports. While accidents account for more than $50 \%$ of these cases, sudden cardiac deaths (SCD) are less frequent (approx. 15\%), but the leading medical cause of deaths. The risk depends on age, sex, ethnicity, type of sport and sport level. There are large variations in the methods of registration of SCD in recreational and competitive sports. This must be 
taken into account when interpreting reported incidences and causes. High data quality in registries is a prerequisite for meaningful preventive strategies (e.g. ECG screening and safety at sports facilities). This review summarises important results from two national registries on sports-related SCD and shows their potential impact on preventive strategies.

\section{Abstrakt}

Der plötzliche Tod eines jungen Athleten ist das verheerendste medizinische Ereignis im Sport. Während Unfälle mehr als 50\% dieser Fälle ausmachen, sind plötzliche Herztodesfälle zwar seltener (ca. 15\%), aber die häufigste medizinische Todesursache. Das Risiko ist abhängig von Alter, Geschlecht, Ethnizität, Sportart und Sportlevel. Es gibt grosse Unterschiede bei den Registrierungsmethoden von plötzlichen Todesfällen im Freizeit- und Wettkampfsport. Dieses muss bei der Interpretation von publizierten Inzidenzen und Ursachen berücksichtigt werden. Eine hohe Datenqualität in Registern ist Voraussetzung für sinnvolle Vorsorgestrategien (EKG Screening und Sicherheit von Sportstätten). Dieser Übersichtsartikel fasst wichtige Ergebnisse aus zwei nationalen Registern zu sportbezogenen Herztodesfällen zusammen und zeigt mögliche Auswirkungen auf Präventionsstrategien auf.

\section{Introduction}

Sports-related sudden cardiac arrest (SrSCA) and sudden cardiac death (SrSCD), particularly among world reknown athletes, attract huge public attention and considerable scientific interest.

An annual incidence of about 0,7-3,0 per 100000 athletes have been reported in young competitive athletes $<35$ years, although a wide range of incidences has been described

[1-4]. Contrasts in current estimates are due to differing methodologies of registering and comparison of heterogeneous populations [5,6]. The US Registry for Sudden Death in Athletes calculated the incidence of SCD for US athletes aged 8-39 as 1:164 000 [2]. In a prospective, observational study in Italy from 1979 to 1999 using regional registry data with mandatory reporting systems, the reported rate of SCD was 1:43 478 in athletes aged 12-35 [1]. The disparity in incidence numbers between Italy and the USA may be due to the differing ethnic populations. However, different methods of measuring incidence with retrospective cohorts based on media reports and registries versus a prospective mandatory reporting system with a reliable denominator may also play an important role [5]. A study analysing the incidence of SCD associated with half-marathon and marathon races came to a very low incidence rate with 0,5 per 100000 [4], whereas recent data from US college athletes demonstrated an overall incidence rate of 1:53 703 with further identification of high-risk subgroups such as men (1:37 790), black athletes (1:21 491) and basketball players (1:5200) [7]. The incidence of SCD in older athletes $>35$ years is expected to rise as a growing number of older individuals takes part in organized sports and competitive sports events [8,9]. The aetiology of SCD from different studies conducted in different parts of the world varies greatly. The most common causes in young athletes $<35$ years are genetic or congenital cardiovascular abnormalities. Hypertrophic cardiomyopathy (HCM) accounts for the majority of fatal cases in several North American studies, whereas arrhythmogenic right ventricular cardiomyopathy (ARVC) was responsible for up to one quarter of SrSCDs in the Veneto region [2,10-12].

Other causes of SrSCD in younger athletes include coronary artery anomaly (CAA), dilated cardiomyopathy (DCM) and to a lesser extent myocardial bridging [2,13]. Myocarditis, typically caused by viral infections, is 
considered to be the cause of death in around 3-8\% of athletes but may be underestimated in certain subpopulations [2,3,14]. Recent data from a UK Regional SCD-Registry demonstrated a high prevalence of sudden arrhythmic death syndrome (SADS) in young athletes, underlining the importance of inherited primary arrhythmia syndromes as a major cause of SCD in athletes [15]. Data in national college athletes also showed that the most common finding at autopsy is a structurally normal heart, implying that electrical disorders may be the most common aetiology [7].

In older athletes, coronary artery disease (CAD) is the most common cause of SrSCD, identified in more than $80 \%$ of cases [8,16-18]. However, a study has found that CAD already represents the main risk factor for SCD in the age group 25-35 [19].

Prospective national registries examining the incidence and aetiology of SrSCD not only in competitive athletes but also in recreational sports participants have been established in very few countries only [9,20,21]. However, taking into account the variations in terms of incidence and particularly aetiology between different countries or even regions within countries, there are convincing theoretical reasons to investigate regional distribution patterns of cardiovascular causes of SD. Genetic (ethnic mix) and environmental factors may vary which can have a considerable impact on SrSCD aetiology and the makeup of screening programmes.

\section{German registry of sports-related sudden cardiac arrests}

Methods

The prospective German SrSCA registry was established in May 2012 under the auspices of the German Society of Cardiology (Deutsche Gesellschaft für Kardiologie) and is funded by the German Heart Foundation (Deutsche Herzstiftung).

\section{Definitions}

SrSCD was defined as death occurring during sports activity or up to 1 hour after its cessation. Survived SrSCA was defined as cardiac arrest that occurred during sport or within 1 hour after its cessation with survival of the subject after cardiopulmonary resuscitation (CPR)/defibrillation. SrSCAs related to trauma - apart from commotio cordis - were excluded. We included subjects 10 to 79 years old because physical activity according to our definition is very difficult to assess in the very young, and those older than 79 years only rarely participate in sports. We defined 3 different levels of sport:

1. Elite competitive athletes were defined as subjects younger than 40 years who participate in an organized team or individual sport that requires voluminous and intensive systematic training and regular competition against others with training focussing on athletic excellence and achievement.

2. Non-elite competitive athletes were defined as subjects of any age who participate in organized lower level competitive events, either in a team or individually.

3. A recreational athlete was defined as an individual who participates in recreational sport without competition against others, on either a regular or non-regular basis.

Four different ways of case detection were used. Firstly, we established a confidential web-based data 
platform which records SCD and survived SCA cases occurring during sports activity or up to 1 hour after its cessation (www.scd-deutschland.de). Reporting of cases was possible for observers such as relatives, other athletes, coaches, journalists as well as for medical doctors via an "online access". Following the entry, contact was established with the reporting person to get more detailed information on the circumstances of the incident.

Secondly, we cooperated with the German Resuscitation Registry of out-of-hospital cardiac arrests in Germany. Any sports-related case detected by the German Resuscitation Registry, was transferred to our registry.

Additionally, we used a systematic web-based medium monitoring via Press-Monitoring-Screening (PMG), the largest German-speaking press database, on a weekly basis. With a combination of key words including heart-related terms or activities (e.g. SCA/SCD, myocardial infarction, myocarditis, exercise, athletes, prevention), cases could be filtered out that occurred in relation to sports activity. Finally, we cooperated with 15 regional institutes of forensic medicine in Germany. A definitive cause of death could only be determined in cases in which an autopsy had been performed or in which the diagnosis could be obtained with clinical certainty. In Germany, an autopsy is not mandatory by law and is only carried out if the death is regarded as potentially suspicious of having an unnatural cause by the physician certifying the death and/or by the Public Prosecution Service.

\section{Results}

After 2 years and 6 months of observation, a total of 144 cases were recorded of which 38 subjects survived [14]. 44 cases were reported via online access and 101 cases were found via Press-Monitoring-Screening (one double case-detection). No SrSCD was reported by the different regional institutes of forensic medicine. The overall incidence of SrSCA for sports participants $\geq 18$ years was 1,2 per million per year (Robert-Koch Institute (RKI) data). The incidence for male sports participants $\geq 18$ years was calculated as 1,6 per million per year, whereas female athletes had a significantly lower incidence with 0,06 per million per year. Adolescents under the age of 18 years had an incidence of SrSCA of 0,4 per million per year. When calculating with the German Socio-Economic Panel (SOEP) data, the overall incidence of SrSCA for sports participants $\geq 17$ years was 1,5 per million per year.

125 (87\%) of SrSCAs were witnessed, of which 108 (75\%) occurred in public sports facilities (such as a stadium, sport club or organised running event e.g.) and 125 (87\%) were witnessed. Prompt CPR was initiated in 118 subjects (82\%). The initial cardiac rhythm was ventricular fibrillation (VF) or pulseless fast ventricular tachycardia in 48 cases and asystole in 7 cases (89 cases remaining unclear). 96 subjects (67\%) were transferred to a hospital. SrSCA mostly occurred during sports activity (122 cases, 85\%). Only 22 cases (15\%) occurred up to 1 hour after sports cessation. The majority of cases occurred in non-elite competitive or recreational athletes $(n=142,99 \%)$. Only 2 cases occurred in young professional elite athletes. Most SrSCAs were observed during football or running which represent the most popular sport disciplines in Germany.

The mean age of the SrSCA subjects was $46,8 \pm 16,2$ years. $97 \%$ were men. In the majority of cases in which it was possible to obtain the cause of death with clinical certainty or from forensic investigations $(n=66)$ the cause of death was of cardiovascular origin $(n=64,97 \%)$. Myocardial infarction was the most frequent cause of SrSCA ( $n=34$, mean age 48,2 $\pm 10,6$ years). Nine subjects showed severe coronary stenosis at 
coronary angiography that most likely resulted in a demand ischemia (e.g. ischemia due to an imbalance between oxygen supply and demand) as a trigger for SrSCA. Myocarditis was diagnosed in 11 subjects with a mean age of 24,5 $\pm 10,4$ years. Only 5 cardiomyopathies could be detected (mean age 20,0 $\pm 11,4$ years) of which 2 were categorized as HCM, 1 as ARVC and 1 as DCM. In 1 case, the cardiomyopathy could not be further classified. CAAs were identified in 3 subjects (mean age 21,3 5,5 years). 2 cardiac ion channelopathies were found (1 long-QT syndrome most likely drug-induced and 1 Brugada syndrome). In 23 cases, the cause of death could not be established by means of autopsy or invasive/non-invasive cardiac imaging. Of these, 8 subjects had a known CAD (all of them with a past myocardial infarction), meaning that an ischemic cardiovascular event can be assumed. Seven subjects had $\geq 1$ cardiovascular risk factor which implied a likelihood for a cardiovascular event. Eight subjects had chest pain/dyspnoea temporally related to the SCA. Therefore, these 23 cases were placed in the category ,likely CAD'. The two non-cardiac causes were one pulmonary embolism and one subarachnoid haemorrhage.

In the age group > 35 years, CAD predominated by far. Amongst our younger victims, we observed 37 cases in subjects $\leq 35$ years. Myocarditis prevailed in this age group, followed by premature CAD. All cardiomyopathies and CAAs occurred in the group of athletes $\leq 35$ years. In total, 28 post-mortem examinations of the heart with detailed histopathological examination had been carried out of which 18 had been performed in athletes $\leq 35$ years. Five of them - all in the age group $\leq 35$ years - remained without conclusive diagnosis. In these cases, post-mortem molecular analysis had not been performed.

\section{Swiss registry of sports-related sudden cardiac deaths}

\section{Methods}

The Swiss REGistry of Athletic Related Death (www.swissregard.ch) was established in 2011 as part of a multidisciplinary working group (Forensic Medicine, Medical Genetics and Cardiology) on sudden cardiac death [22,23]. In a first study all forensic autopsy reports of the German-speaking part of Switzerland (population in the included region comprises nearly 70\% of the 8,5 million Swiss population) from 1999 to 2010 were retrospectively reviewed for sudden unexpected deaths in individuals aged 10-39 years.

\section{Definitions}

Cases of SCD were classified into three categories based on whether or not sports were performed within the 24-hours preceding the SCD: no sports (NONE), recreational sports (REC), or competitive sports (COMP). SrSCDs were included in COMP if they were related to official athletic competitions including organized team or individual sports events. All other SrSCDs were categorized as REC. The timing of SCD was related to the onset of symptoms in SCDs not related to sports (NONE) or the physical activity in SCDs related to sports participation (REC, COM). Timing was classified into three groups: instantaneous, within one hour, and within 24-hours. Examination of the heart was performed by local forensic pathologists, and the postmortem diagnosis was based on macroscopic findings. When needed, microscopic and toxicological examinations were performed to clarify the underlying pathology. The criterion for hemodynamically relevant CAD was a lumen narrowing of $\geq 50 \%$ [24]. 
Results

Overall, 82 women (23,5\%) and 267 men (76,5\%) aged $10 \pm 39$ years suffered a SCD in the German-speaking part of Switzerland, accounting for an overall incidence of 2,89/100 000 person-years (mean age \pm SD, 30 \pm 7 years; 76,5\% male). Among all 349 individuals, 297 (85,1\%) deceased without an obvious connection to physical exercise (NONE), 31 cases (8,9\%) were related to recreational sports (REC) and 21 (6\%) to competitive sports (COMP). Incidences of SCD per 100000 person years [mean (95\% CI)] were the lowest in REC [0,43 (0,35-0,56)], followed by COMP [1,19 (0,89-1,60)] and the highest in NONE [2,46 $(2,27-2,66)]$. The incidence of SCD unrelated to sports (NONE) was nearly 4 times higher compared to sports-related SCD $(2,46$ vs. 0,59$)$ [24]. There were no differences in incidences of SrSCD between sports of different static and dynamic components of exercise [25].

There was a predominance of male victims in all three categories, with no significant difference in mean age of subjects between groups ( $\mathrm{p}=0,732)$. The proportions of males in REC $(96,8 \%)$ and in COMP $(85,7 \%)$ were greater than in NONE (73,7\%) ( $p=0,009)$. Out of 52 sports-related deaths, 48 occurred in men $(92,3 \%)$. Three professional male athletes were included in COMP, aged 26, 28 and 30 years. The majority of SCDs occurred instantaneously or within 1 hour after the onset of initial symptoms or sports. This tendency was the highest in REC (87,1\%), and higher in COMP $(85,7 \%)$ than in NONE $(53,9 \%)$. The highest rate of witnessed cases was observed in COMP (85,7\%), followed by REC (64,5\%) and NONE (42,7\%) [24]. CAD with or without acute myocardial infarction (MI) was the most common causative pathology in all three groups; cause-specific incidences were $0,91(0,80-1,03), 0,11(0,07-0,18)$, and $0,45(0,28-0,73)$ for NONE, REC and COMP, respectively (Figure 1). Overall, premature CAD accounted for death of 126 young individuals ( $89 \%$ male; $52 \% \leq 35$ years), comprising $36 \%$ of all SCDs. Amongst all sports-related SCDs, $13,4 \%$ were due to acute MI, all cases being observed in victims below 35 years of age. In young male competitive athletes (age $\leq 35$ years) acute MI was the most common cause of SCD. Premature CAD with or without MI was responsible for 8 deaths in COMP, which all occurred instantaneously or within 1-hour of exertion. All females who died from acute MI ( 7 cases) were aged $>25$ years, and none of these deaths were related to sports, while four young men aged $\leq 25$ years died from acute MI. In young women aged $\leq 35$ years, cardiomyopathies were the leading pathological substrate for SCD (40,7\% of cases). In older females, CAD was the most commonly observed (42\%). Death of three women was related to participation in competitive sports (COMP); they succumbed to death due to Wolf Parkinson White (WPW) syndrome, myocarditis or valvular heart disease. The only female victim in REC category had a morphologically normal heart on autopsy. Among cardiomyopathies, HCM was the most frequent; incidences in NONE, REC and COMP were $0,24(0,19-0,31), 0,09(0,05-0,15)$ and 0,11 $(0,05-0,29)$, respectively. In around half of SCD victims with underlying HCM, death was related to recreational sports. There were 13 additional cases (12 in NONE and 1 in REC) where autopsy revealed myocardial fibrosis and (borderline) left-ventricular hypertrophy, which could possibly have been HCM; these were classified in a separate group (possible HCM/fibrosis) due to unfulfilled histologic criteria (myocardial disarray) for post-mortem definite diagnosis of HCM. Sportsrelated SCDs from other underlying cardiomyopathies were rare, only $13 \%$ of sports-related deaths were due to dilated cardiomyopathy (DCM), ARVC or any other cardiomyopathy. ARVC was considered the causative pathology in 2 cases, one in REC and one in COMP. All victims of ARVC and coronary artery anomalies were aged 35 years or younger. Two of the three professional athletes died during wrestling and one during ice hockey. No time trend for total or cause-specific incidences of SCD was found in any of the 
groups (Figure 1) [24].

\section{Pre-screening period Screening period}

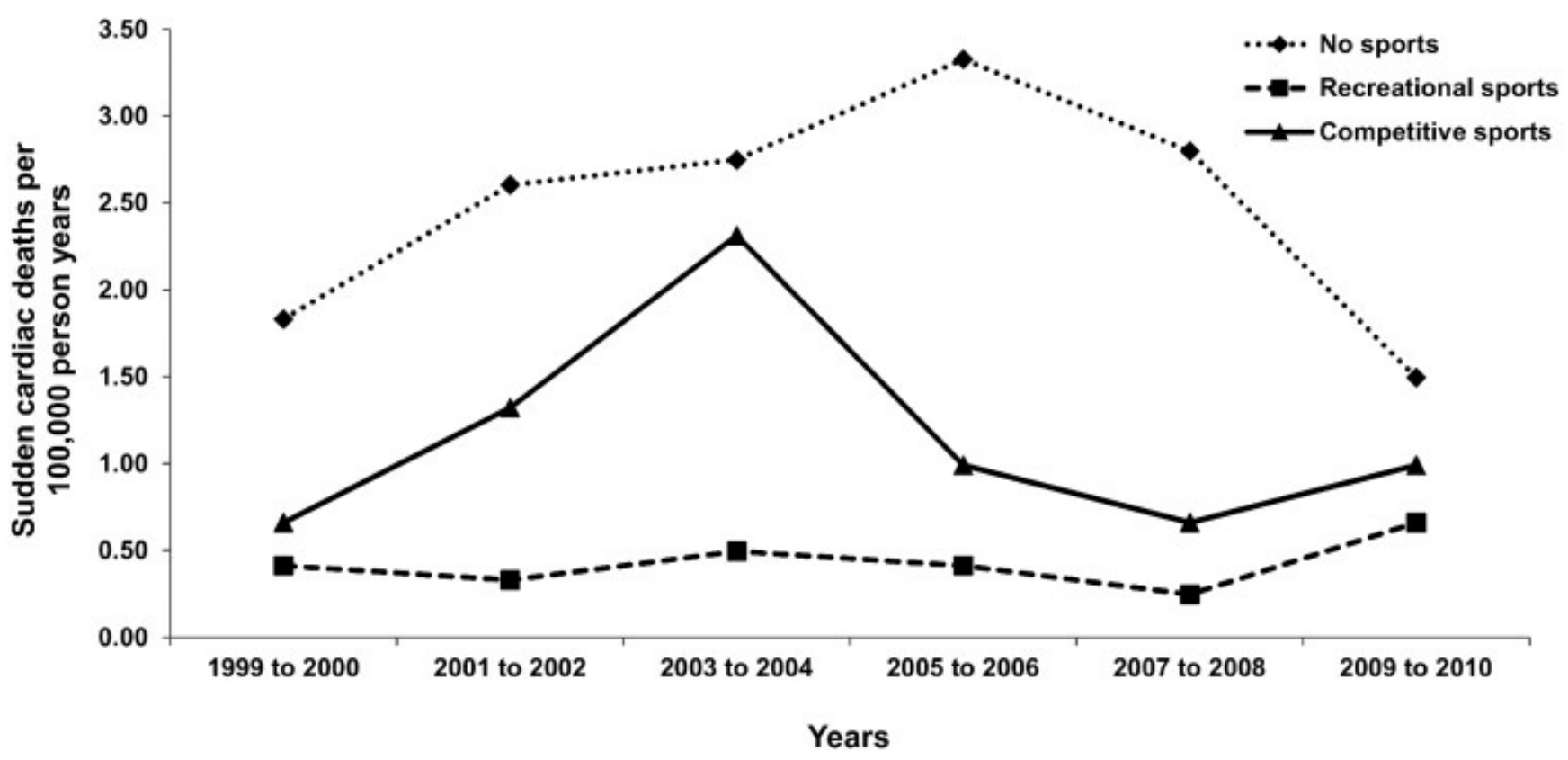

Figure 1: Time trends of incidences of sudden cardiac deaths in Switzerland and their association with recreational or competitive sports. Following the introduction of ECG screening of selected competitive athletes groups in Switzerland, there appeared to be a trend towards a lower incidence of SCD in competitive sports. However, the comparison with

the incidence in the pre-screening period suggests that this finding is more likely due to annual variations of incidences rather than a causal association.

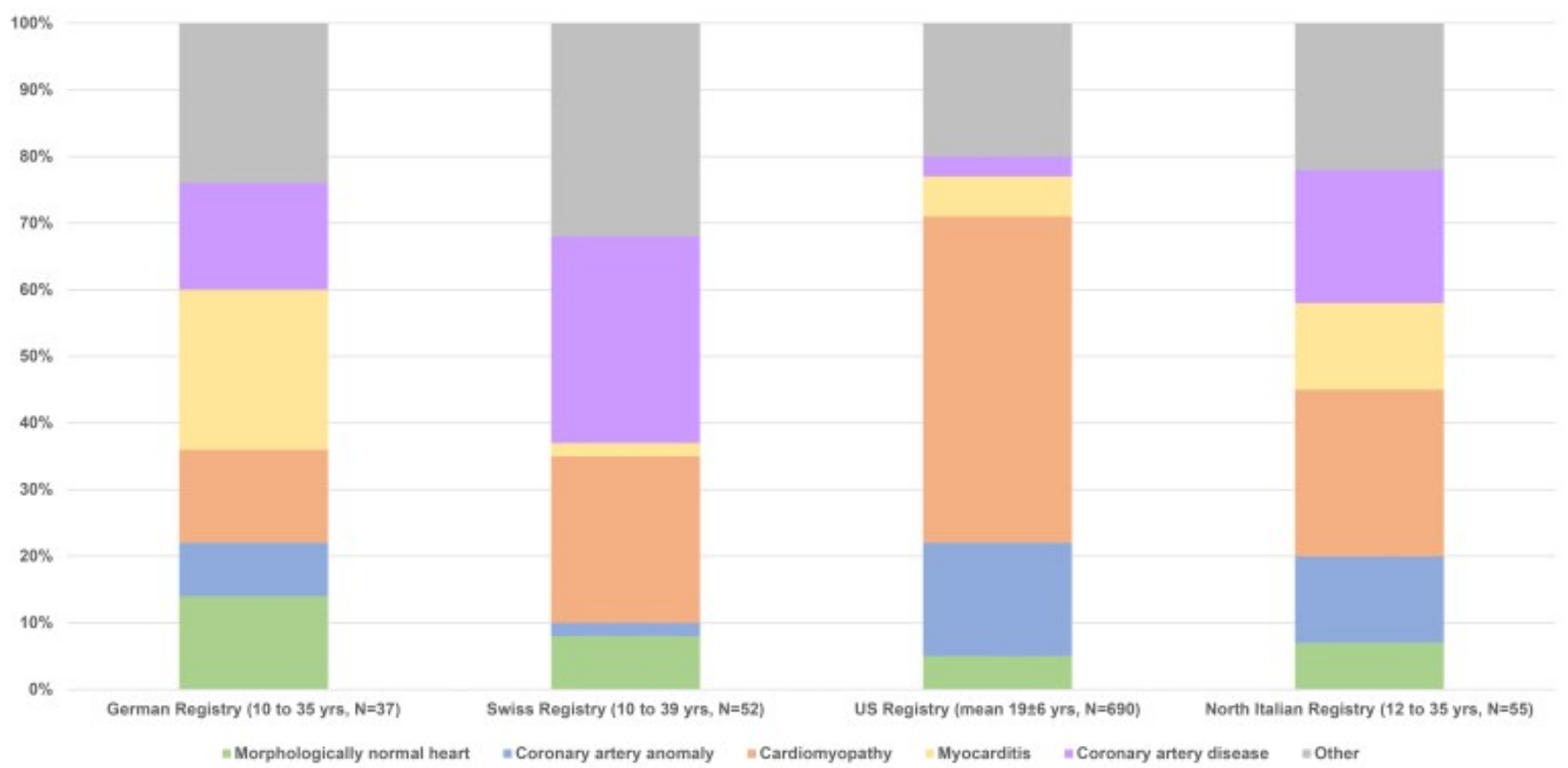

Figure 2: Distribution of causes of sports-related sudden cardiac death in young athletes from four registries. The most 


\section{Discussion}

Both the German and the Swiss registry confirmed an overall low incidence of SrSCD in young individuals, even if a methodology-related underreporting is taken into account. An advantage of the German registry is the collection of both SrSCD and SrSCA, with more diagnostic possibilities for the latter. The observed predominance of male victims ( $>90 \%$ ) is consistent with other reports [2,26,27]. However, both registries challenge the assumption that cardiomyopathies are the most common underlying cause of SCD in young competitive athletes, which is usually used as an argument for pre-participation screening with an electrocardiogram (ECG) in this population [26]. Myocarditis and CAD were the most common causes of SrSCD in Germany and Switzerland (Figure 2).

The results have to be interpreted with caution, since both registries have some limitations, namely risk of underestimation of the true burden of SrSCD and potential misclassification of cases. Most of the cases in the German registry (70\%) were registered via Press-Monitoring-Screening, and autopsy was not performed in all young SCD victims (67\%) to confirm the cause of death [14]. In the Swiss registry, only cases from Institutes of Forensic Medicine were analysed, and in the absence of mandatory autopsy the autopsy rate was low (47,5\%). Moreover, autopsies were performed by forensic pathologists, who are not necessarily specialized in cardiovascular pathology [24].

\section{Conclusion}

Despite methodological limitations in both registries, valuable information for risk-based screening and preventive strategies in young athletes were collected. It is unlikely that the distribution pattern of underlying cardiac diseases would change with higher incidences. The male predominance of SrSCD would allow a less strict follow-up strategy of healthy female athletes without symptoms. The high incidence of myocarditis in the German registry should stimulate the debate of an appropriate follow-up and return-to-play strategy in athletes with suspected viral infections, including education of athletes and trainers. The observation that CAD was a major cause of death in young individuals ( $<35$ years) in both registries is supported by other reports [27,28], and may give grounds to question the traditional age cutoff of 35 years separating younger from older athletes. It could be used as an argument for a one-time lipid profile in the pre-participation screening protocol, although there is currently insufficient evidence from the general population to support this approach [29]. The finding of a high proportion of causes not detectable by ECG screening is one plausible explanation why in Switzerland the implementation of ECGscreening in competitive athletes failed to reproduce the results reported in the North Italian registry (Figure 1). The $89 \%$ decrease of SrSCD in the Veneto region of Italy after implementation of an ECG screening programme was driven by a reduction of ARCV, but not of CAD cases [26]. It highlights the importance of additional preventive strategies, like arena safety [30], and public education on basic life support including the appropriate use of an automated external defibrillator (AED). 


\section{First Author}

Dr. med. Philipp Bohm

Email: philipp.bohm@usz.ch

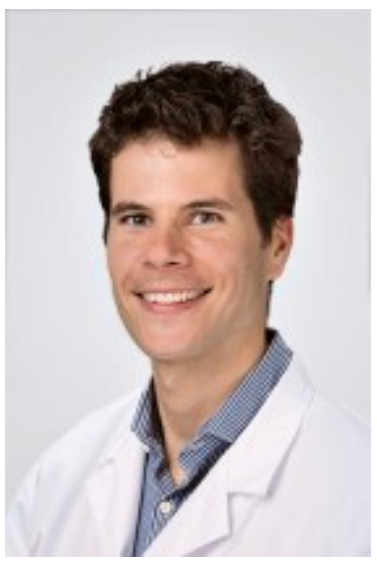

\section{Corresponding Author}

Prof. Dr. med. Matthias Wilhelm

Tel: 0041316328986

Email: matthias.wilhelm@insel.ch

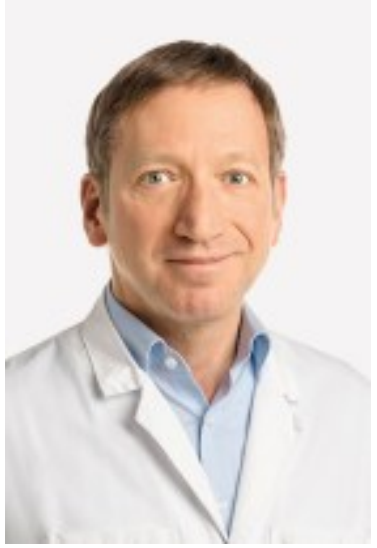

\section{References}

1. Corrado D, Basso C, Rizzoli G, Schiavon M, Thiene G. Does sports activity enhance the risk of sudden death in adolescents and young adults? J Am Coll Cardiol. 2003;42(11):1959-63.

2. Maron BJ, Doerer JJ, Haas TS, Tierney DM, Mueller FO. Sudden deaths in young competitive athletes: analysis of 1866 deaths in the United States, 1980-2006. Circulation. 2009;119(8):1085-92. 
3. Eckart RE, Scoville SL, Campbell CL, Shry EA, Stajduhar KC, Potter RN, et al. Sudden death in young adults: a 25-year review of autopsies in military recruits. Ann Intern Med. 2004;141(11):829-34.

4. Kim JH, Malhotra R, Chiampas G, d'Hemecourt P, Troyanos C, Cianca J, et al. Cardiac arrest during long-distance running races. N Engl J Med. 2012;366(2):130-40.

5. Harmon KG, Drezner JA, Wilson MG, Sharma S. Incidence of sudden cardiac death in athletes: a stateof-the-art review. Heart. 2014; 100(16):1227-34.

6. Solberg EE, Borjesson M, Sharma S, Papadakis M, Wilhelm M, Drezner JA, et al. Sudden cardiac arrest in sports - need for uniform registration: A Position Paper from the Sport Cardiology Section of the European Association for Cardiovascular Prevention and Rehabilitation. Eur J Prev Cardiol. 2016;23(6):657-67.

7. Harmon KG, Asif IM, Maleszewski JJ, Owens DS, Prutkin JM, Salerno JC, et al. Incidence, Cause, and Comparative Frequency of Sudden Cardiac Death in National Collegiate Athletic Association Athletes: A Decade in Review. Circulation. 2015;132(1):10-9.

8. Chugh SS, Weiss JB. Sudden Cardiac Death in the Older Athlete. J Am Coll Cardiol. 2015;65(5):493-502.

9. Marijon E, Tafflet M, Celermajer DS, Dumas F, Perier MC, Mustafic H, et al. Sports-related sudden death in the general population. Circulation. 2011;124(6):672-81.

10. Maron BJ. Sudden death in young athletes. N Engl J Med. 2003; 349(11):1064-75.

11. Corrado D, Basso C, Schiavon M, Thiene G. Screening for hypertrophic cardiomyopathy in young athletes. N Engl J Med. 1998;339(6):364-9.

12. Corrado D, Basso C, Thiene G. Essay: Sudden death in young athletes. Lancet. 2005;366 Suppl 1:S47-8.

13. Schmied C, Borjesson M. Sudden cardiac death in athletes. Journal of internal medicine. 2014;275(2):93-103.

14. Bohm P, Scharhag J, Meyer T. Data from a nationwide registry on sports-related sudden cardiac deaths in Germany. Eur J Prev Cardiol. 2016;23(6):649-56.

15. Finocchiaro G, Papadakis M, Robertus JL, Dhutia H, Steriotis AK, Tome M, et al. Etiology of Sudden Death in Sports: Insights From a United Kingdom Regional Registry. J Am Coll Cardiol. 2016; 67(18):2108-15.

16. Corrado D, Schmied C, Basso C, Borjesson M, Schiavon M, Pelliccia A, et al. Risk of sports: do we need a pre-participation screening for competitive and leisure athletes? Eur Heart J. 2011;32(8):934-44.

17. Waller BF, Roberts WC. Sudden death while running in conditioned runners aged 40 years or over. Am J Cardiol. 1980;45(6):1292-300.

18. Suarez-Mier MP, Aguilera B, Mosquera RM, Sanchez-de-Leon MS. Pathology of sudden death during recreational sports in Spain. Forensic science international. 2013;226(1-3):188-96.

19. Meyer L, Stubbs B, Fahrenbruch C, Maeda C, Harmon K, Eisenberg M, et al. Incidence, causes, and survival trends from cardiovascularrelated sudden cardiac arrest in children and young adults 0 to 35 years of age: a 30-year review. Circulation. 2012;126(11):1363-72.

20. Marijon E, Uy-Evanado A, Reinier K, Teodorescu C, Narayanan K, Jouven X, et al. Sudden Cardiac Arrest During Sports Activity in Middle Age. Circulation. 2015;131(16):1384-91.

21. Berdowski J, de Beus MF, Blom M, Bardai A, Bots ML, Doevendans PA, et al. Exercise-related out-ofhospital cardiac arrest in the general population: incidence and prognosis. Eur Heart J. 2013;34(47):3616-23.

22. Wilhelm M, Bolliger SA, Bartsch C, Fokstuen S, Grani C, Martos V, et al. Sudden cardiac death in forensic medicine - Swiss recommendations for a multidisciplinary approach. Swiss Med Wkly. 2015; 145:w14129.

23. Wilhelm M, Kellerhals C, Bolliger S, Schmied C, Wyler D, Nagel R, et al. Swissregard.ch - a prospective registry on sudden death and aborted sudden cardiac death in Swiss athletes. Schweiz Zeitschr Sportmed Sporttrauma. 2011;59(2):96-8.

24. Asatryan B, Vital C, Kellerhals C, Medeiros-Domingo A, Grani C, Trachsel LD, et al. Sports-related 
sudden cardiac deaths in the young population of Switzerland. PLoS One. 2017;12(3):e0174434.

25. Grani C, Chappex N, Fracasso T, Vital C, Kellerhals C, Schmied C, et al. Sports-related sudden cardiac death in Switzerland classified by static and dynamic components of exercise. Eur J Prev Cardiol. 2016;23(11):1228-36.

26. Corrado D, Basso C, Pavei A, Michieli P, Schiavon M, Thiene G. Trends in sudden cardiovascular death in young competitive athletes after implementation of a preparticipation screening program. JAMA. 2006;296(13):1593-601.

27. Risgaard B, Winkel BG, Jabbari R, Glinge C, Ingemann-Hansen O, Thomsen JL, et al. Sports-related sudden cardiac death in a competitive and a noncompetitive athlete population aged 12 to 49 years: Data from an unselected nationwide study in Denmark. Heart rhythm : the official journal of the Heart Rhythm Society. 2014;11(10):1673-81.

28. Bagnall RD, Weintraub RG, Ingles J, Duflou J, Yeates L, Lam L, et al. A Prospective Study of Sudden Cardiac Death among Children and Young Adults. N Engl J Med. 2016;374(25):2441-52.

29. Force USPST, Bibbins-Domingo K, Grossman DC, Curry SJ, Davidson KW, Epling JW, Jr., et al. Screening for Lipid Disorders in Children and Adolescents: US Preventive Services Task Force Recommendation Statement. JAMA. 2016;316(6):625-33.

30. Borjesson M, Dugmore D, Mellwig KP, van Buuren F, Serratosa L, Solberg EE, et al. Time for action regarding cardiovascular emergency care at sports arenas: a lesson from the Arena study. European heart journal. 2010;31(12):1438-41. 